\title{
Relaxation of ceramic tile stresses generated by fast drying: a kinetic model
}

\author{
Amorós, J.L. ${ }^{\text {a b }}$; Cantavella, V.c ; Blasco, E. ${ }^{\text {a* }}$ \\ a Instituto de Tecnología Cerámica - Asociación de Investigación de las Industrias Cerámicas. \\ ${ }^{\mathrm{b}}$ Department of Chemical Engineering. Universitat Jaume I, Campus Universitario Riu Sec, 12006 \\ Castellon, Spain.

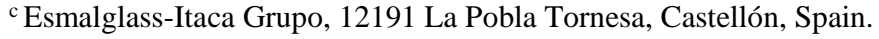

*E-mail of the corresponding author: encarna.blasco@itc.uji.es

\begin{abstract}
Unfired tile mechanical properties are very important in the ceramic tile manufacturing process. Inadequate mechanical properties lead to rejects (both in unfired and fired tiles). Unfired tile mechanical strength changes significantly after the tiles exit the industrial dryer. This behaviour can be explained by assuming that the fast-drying process generates stresses in the tile, which subsequently relax. A kinetic model has been derived, based on Maxwell's viscoelastic elements, which explains the development of dried tile mechanical strength. This increases asymptotically when the dried tiles are stored in dry conditions. However, if tiles adsorb humidity (upon exiting the dryer), tile mechanical strength rises and then decreases. This is the result of two opposing phenomena: stress relaxation raises mechanical strength while the concurrent rise in moisture content lowers mechanical strength. The developed model successfully describes this joint mechanical behaviour.
\end{abstract}

Keywords: ceramic tiles, fast drying, stress relaxation, kinetic model. 


\section{Introduction}

Simultaneous heat and mass transport during fast drying (20min) of ceramic tiles produces temperature and, in particular, moisture content gradients in the tiles [1]. Such differential drying would also lead to differential drying shrinkage of the layers if they were not joined together. However, as each individual layer cannot shrink freely, mechanical stresses develop among the layers. Indeed, faster drying of the tile faces generates a moisture content gradient inside the tile, causing the tile faces to be subjected to tensile stresses while the inner tile is under compression. These stresses are not eliminated immediately, so that tile mechanical strength will vary after the tile has been dried and has exited the dryer, as the residual stresses generated during fast drying relax.

This study was undertaken to develop a kinetic model that describes the development of unfired tile mechanical strength after tile drying, both during tile storage in a completely dry and in a humid environment (70\% relative humidity).

\section{Materials and Methods}

Floor tiles measuring $31 \times 31 \times 1 \mathrm{~cm}$, made by industrial pressing of a standard spray-dried powder, were used. Fast drying (20min) was performed in a horizontal industrial dryer. Moisture content and mechanical strength were determined in all test pieces. Mechanical strength was determined by three-point bend testing [2]. Ten tiles were used for each test condition.

\section{Results and discussion}

\subsection{Stress relaxation in dried tiles placed in bags to keep the tiles dry}

Unfired tile mechanical strength, $\sigma_{\mathrm{B}}$, rises considerably during dried tile storage time in bags owing to relaxation of the stresses generated in the tile during drying (Fig. 1). The proposed model that describes these results is based on the following assumptions:

i) The unfired tile is assumed to consist of a series of uniform layers of infinitesimal thickness, each of which is subject to different uniform residual stress.

ii) The viscoelastic behaviour of each layer can be described by a Maxwell element [3].

iii) Total strain is independent of time and position. 


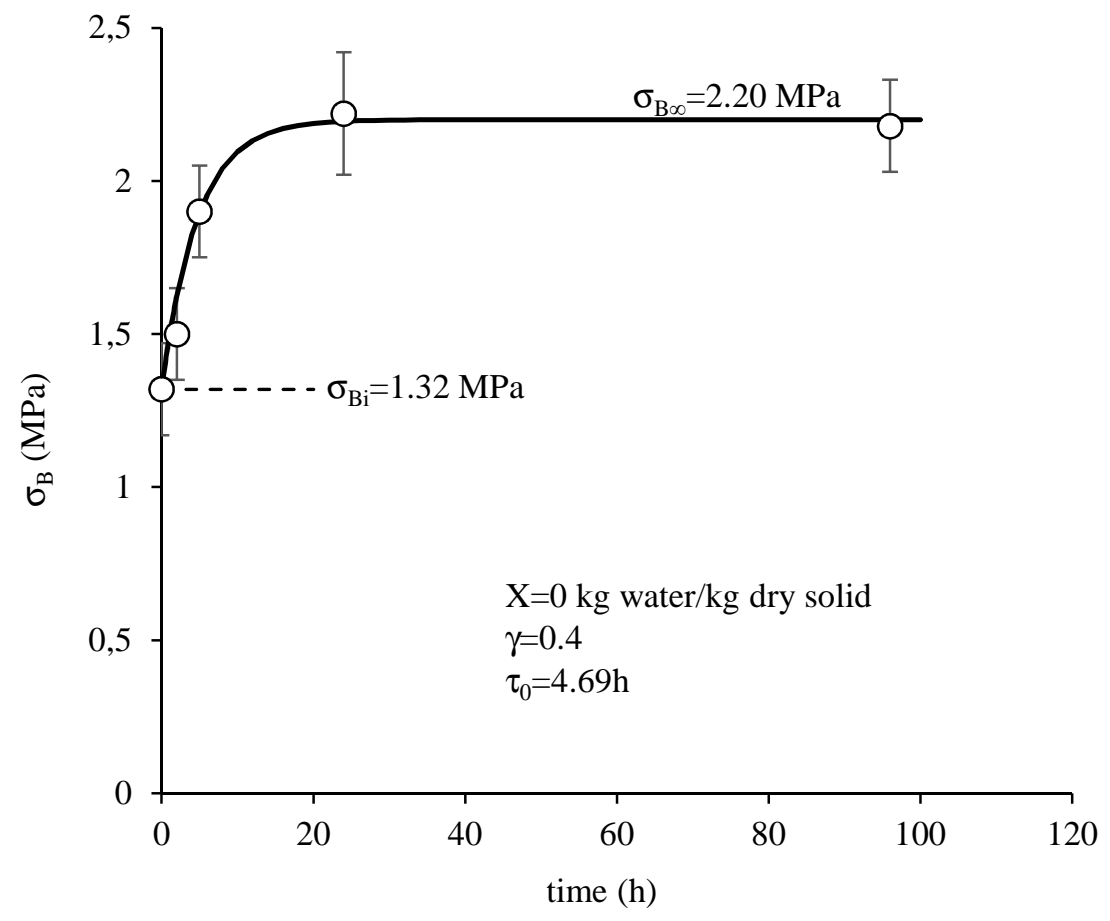

Fig. 1. Variation of the mechanical strength, oB, of dried tiles placed in bags with storage time. Fit of the experimental data to the developed model, Eq. 3.

These assumptions yield the Maxwell model stress relaxation, which describes the evolution of the residual stress, $\sigma$, for a layer:

$$
\sigma=\sigma_{\mathrm{i}} \exp \left(-\frac{\mathrm{t}}{\tau_{0}}\right)
$$

Eq. 1

where $\sigma_{\mathrm{i}}$ is the initial residual stress (at the dryer exit) (MPa) and $\tau_{0}$ is the relaxation time of the dried material (h).

iv) In a bending test, tile mechanical strength, $\sigma_{\mathrm{B}}(\mathrm{MPa})$, is the maximum tensile strength that the bottom layer can withstand. Consequently, during the relaxation process, $\sigma_{\mathrm{B}}$ is the difference between the mechanical strength of the already relaxed layer, $\sigma_{\mathrm{B} \infty}(\mathrm{MPa})$, and the residual stress, $\sigma$, acting upon this layer:

$$
\sigma_{B}=\sigma_{\mathrm{B} \infty}-\sigma
$$

Eq. 2

Introducing Eq. 1 in Eq. 2 yields: 


$$
\sigma_{B}=\sigma_{\mathrm{B} \infty}\left[1-\gamma \exp \left(-\frac{t}{\tau_{0}}\right)\right]
$$

where:

$$
\gamma=\frac{\sigma_{B \infty}-\sigma_{B i}}{\sigma_{B \infty}}
$$

where $\sigma_{\mathrm{Bi}}$ is dried tile mechanical strength at the dryer exit.

This equation describes de evolution, with relaxation time, of the mechanical strength of dried tiles stored in bags to keep the tiles dry (tile moisture content: $\mathrm{X}=0 \mathrm{~kg}$ water/dry solid).

The solid line in Fig. 1 is the plot of Eq. 3. Excellent fit was found.

\subsection{Relationship of relaxed unfired tile mechanical strength, $\sigma_{\mathrm{BR}}$, to moisture content,} $\mathbf{X}$

Fig. 2 shows the mechanical strength of stress-free (relaxed) unfired tiles, $\sigma_{\mathrm{BR}}$, versus moisture content, $\mathrm{X}$, for different experiment series: by moisture adsorption in dried tiles and on drying as-pressed tiles to different moisture contents.

The following equation relates $\sigma_{\mathrm{BR}}$ to moisture content, $\mathrm{X}$, [4] [5]:

$$
\sigma_{\mathrm{BR}}=\sigma_{\mathrm{BR} 0} \exp (-\beta \mathrm{X})
$$

where $\sigma_{\mathrm{BR} 0}$ is the mechanical strength of stress-free dry tiles (MPa) and $\beta$ is a fit parameter.

The solid line in Fig. 2 is the plot of Eq. 5. Excellent fit was found. 


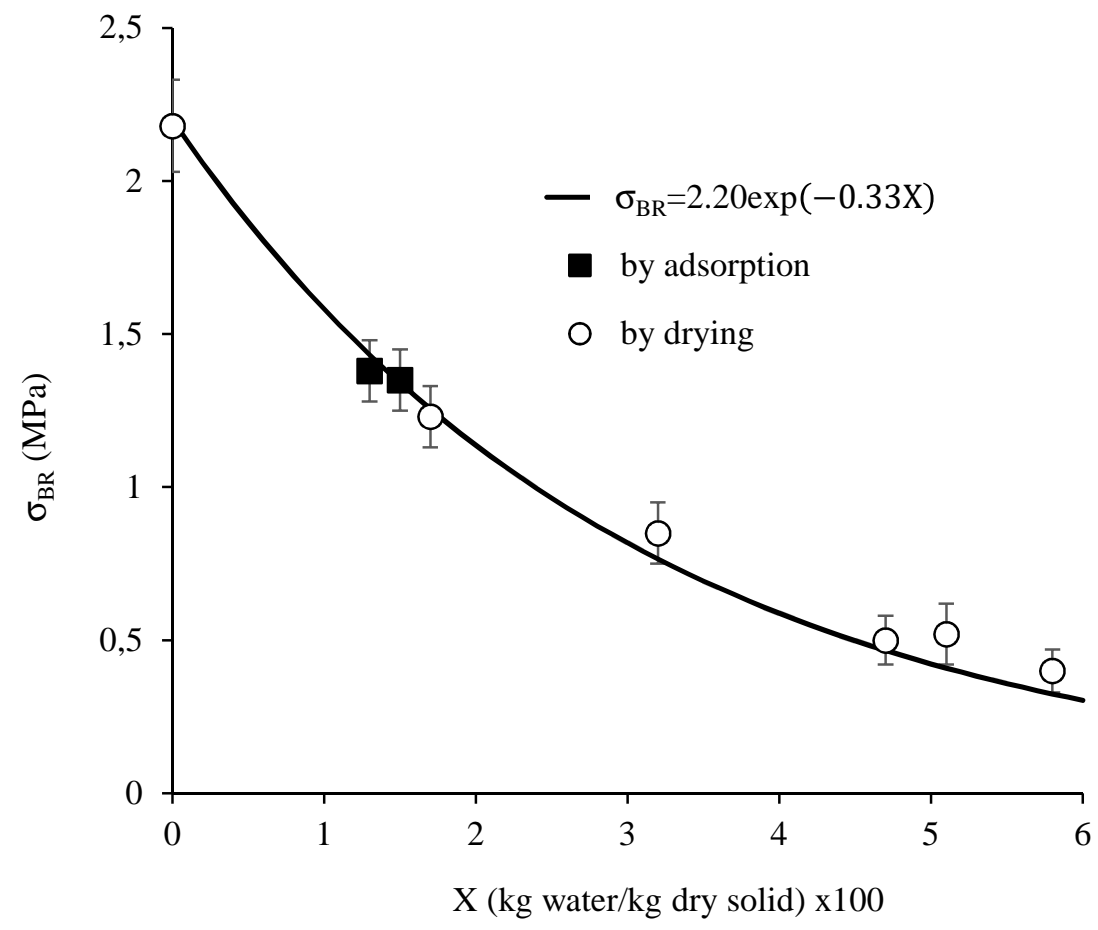

Fig. 2. Effect of moisture content, $X$, on stress-free unfired tile mechanical strength, OBR. Fit of the experimental data to Eq. 5.

\subsection{Development of dried tile mechanical strength on storage in ambient air}

When a tile emerging from the dryer is stored in ambient air $\left(\mathrm{T}=20^{\circ} \mathrm{C}\right.$ and relative humidity=70\%), it will simultaneously be subject to moisture adsorption and stress relaxation. The sum of the opposing effects that each of these phenomena has on unfired tile mechanical strength causes the variation of this property with time to exhibit a maximum value (Fig. 3). 


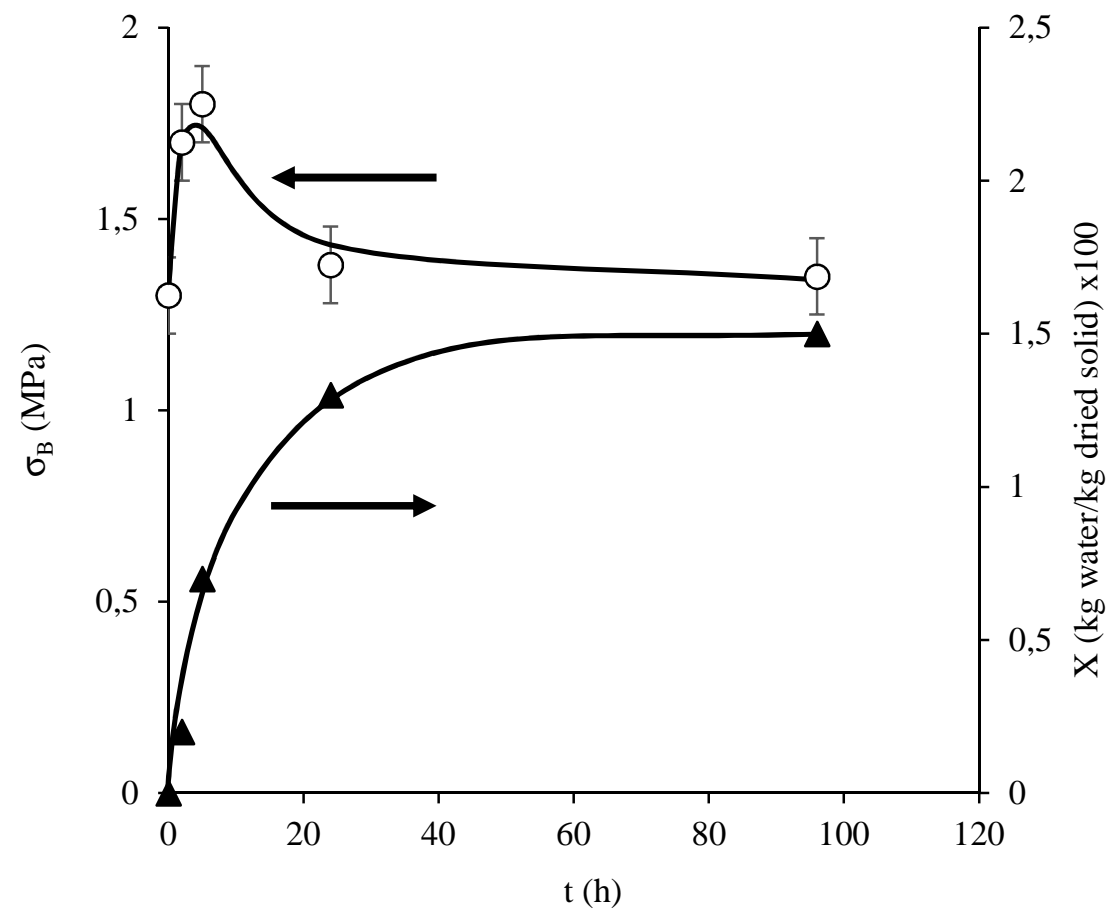

Fig. 3. Variation of dried tile mechanical strength, oB, and moisture content, $X$, with storage time in ambient air $\left(T=20^{\circ} \mathrm{C}\right.$ and relative humidity $\left.=70 \%\right)$.

To derive the model the following modifications must be performed in Eq. 3:

i) As moisture content increases, stress relaxation becomes faster, so that $\tau$ decreases according to the following expression:

$$
\tau^{-1}=\tau_{0}^{-1}+\alpha X
$$

Eq. 6

where $\alpha$ is a fit parameter. Consequently, in Eq. 3, $\tau_{0}$ must be replaced with Eq. 6 .

ii) $\sigma_{\mathrm{B} \infty}$ must be replaced with Eq. 5 .

iii) $\gamma$ does not depend on moisture content, $X$. This parameter is the same as the $\gamma$ calculated in the previous fit to Eq. 3 .

Taking into account the aforementioned assumptions, the final equation becomes:

$$
\sigma_{\mathrm{B}}=\sigma_{\mathrm{BR} 0} \exp (-\beta \mathrm{X})\left[1-\gamma \exp \left(-\left(\frac{1}{\tau_{0}}+\alpha \mathrm{X}\right) \mathrm{t}\right)\right]
$$

For this particular case, substituting the fit parameter values into Eq. 7 yields: 


$$
\sigma_{\mathrm{B}=} 2.20 \exp (-0.33 \mathrm{X})\left[1-0.4 \exp \left(-\left(\frac{1}{4.69}+100 \mathrm{X}\right) \mathrm{t}\right)\right]
$$

The agreement between Eq. 8 and the experimental data is good (Fig. 3). The equation reproduces the peak strength attained after a certain time.

\section{Conclusions}

Unfired ceramic tile mechanical strength changes significantly after the tiles exit the industrial dryer. Dried tile mechanical strength increases asymptotically when the tiles are stored in dry conditions. When these tiles adsorb humidity, tile mechanical strength exhibits a peak.

A model has been developed, based on Maxwell's viscoelastic element, which successfully describes this mechanical behaviour.

The relationship between the mechanical strength of stress-free unfired tiles and tile moisture content was found to be independent of whether the process involved modifying tile moisture content by drying or by moisture adsorption.

\section{References}

[1] Mallol, G.; Cantavella, V.; Llorens, D.; Feliu, C., "Study of ceramic tile drying under non-isothermal conditions and its industrial applications," in Proceedings of the 7th Conference and Exhibition of the European Ceramic Society, Uetikon-Zuerich, 2002.

[2] Amorós, J. L.; Cantavella, V.; Jarque, J. C.; Feliu, C., "Green strength testing of pressed compacts: an analysis of different methods," Journal of the European Ceramic Society, no. 28, p. 701-710, 2008.

[3] Moreno, R., Reología de suspensiones cerámicas, Madrid: Consejo Superior de Investigaciones Científicas (CSIC), 2005.

[4] Amorós, J. L., Pastas cerámicas para pavimentos de monococción. Influencia de las variables de prensado sobre las propiedades de la pieza en crudo y sobre su comportamiento durante el prensado y la cocción, Burjasot: PhD Thesis. Universidad de Valencia, 1987.

[5] Jarque, J. C., Estudio del comportamiento mecánico de soportes cerámicos crudos: mejora de sus propiedades mecánicas, Castellón: PhD thesis. Universitat Jaume I, 2001. 